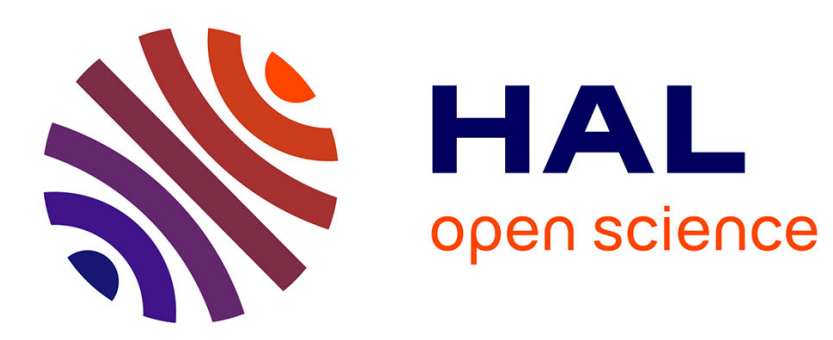

\title{
Orientation in French spatial expressions: formal representations and inferences
}

Michel Aurnague

\section{To cite this version:}

Michel Aurnague. Orientation in French spatial expressions: formal representations and inferences. Journal of Semantics, 1995, 12 (3), pp.239-267. hal-00462597

\section{HAL Id: hal-00462597 \\ https://hal.science/hal-00462597}

Submitted on 10 Mar 2010

HAL is a multi-disciplinary open access archive for the deposit and dissemination of scientific research documents, whether they are published or not. The documents may come from teaching and research institutions in France or abroad, or from public or private research centers.
L'archive ouverte pluridisciplinaire HAL, est destinée au dépôt et à la diffusion de documents scientifiques de niveau recherche, publiés ou non, émanant des établissements d'enseignement et de recherche français ou étrangers, des laboratoires publics ou privés. 


\title{
Orientation in French spatial expressions: formal representations and inferences
}

\author{
Michel Aurnague \\ Equipe de Recherche en Syntaxe et Sémantique - CNRS \\ Université de Toulouse- Le Mirail
}

\begin{abstract}
In this paper we propose several formal tools intended to grasp an important aspect of static localisation in language namely orientation. We consider French spatial expressions used in localising an entity in an internal way (Internal Localisation Nouns such as haut (top), bas (bottom), devant (front), derrière (back)) or in an external way (prepositions devant (in front of), derrière (behind), au-dessus de (above), au-dessous de (below)). In order to represent these orientation phenomena, we build a logical framework made up of three levels that we call geometrical, functional and pragmatic. First, we define a geometry based on directions and relative localisation operators. Then, we introduce the functional notions that underly intrinsic orientation processes and we propose several formal definitions which may serve to represent the semantic content of the studied lexemes. These definitions allow us to make a difference between deictic and intrinsic uses of these spatial expressions and to draw interesting deductions and inferences. Finally, we integrate at the pragmatic level various principles governing the interpretation of such orientational expressions. By taking into account the different inferential schemata linked to the use of spatial expressions in discourse, this modular approach constitutes an original contribution to the semantic and cognitive studies of linguistic space.
\end{abstract}

\section{1- Introduction}

This work on orientation ${ }^{1}$ comes within the framework of research in spatial semantics developed over past 10 years both in cognitive linguistics (Bierwich \& Lang 89) (Herskovits 86) (Lang 90) (Talmy 83) (Vandeloise 86a) and computational semantics (Habel 87) (Pribbenow 93). It is part of a broader project which aims at giving a formal representation of the semantic content of French linguistic markers of space (Borillo M. 91). In the category of referents, this project has dealt with Internal Localisation Nouns (henceforth ILN) such as haut (top), avant (front), intérieur (inside), bord (edge) which are all lexical elements pointing to the different portions of an object. As for spatial relations, we examined internal and external prepositions (sur (on), dans (in)/devant (in front of), au-dessus de (above), etc.) as well as several verbs of motion (se diriger vers (to go towards), venir de (to come from), passer par 
(to go through)).

A semantic analysis of these lexemes highlighted some important properties of spatial structures in language (Asher \& Sablayrolles 95) (Aurnague 89) (Aurnague \& Vieu 93) (Borillo A. 88) (Borillo A. 92) (Laur 91). On the basis of these observations, a formal system of representation of spatial entities and relations was proposed which consists of three levels encoding geometrical, functional and pragmatic data.

Orientation does in fact play a great part in the semantics of most of these ILNs as well as in the semantics of prepositions such as sur (on), au-dessus de (above), derrière (behind), etc. (that is to say, in both referent and relation categories and in both internal and external cases). We present in this paper a formal treatment of orientation which improves various aspects of a previous formalisation we gave in (Aurnague 91) and (Aurnague \& Vieu 93) to represent this important feature of spatial semantics. This new formal tool tries to better grasp the differences between deictic and intrinsic orientation, and it can be used to handle both internal and external localisation (le haut (the top)/ au-dessus de (above), l'avant (the front)/devant (in front of), etc.).

Here, we follow the methodological choices that were defined for the whole research project. Firstly, from an empirical point of view, the study has been based on a detailed and systematic linguistic analysis which must highlight and classify the different meanings of each lexeme, in particular, the distinct spatial configurations it refers to. The second point addresses the elaborated formalisms which, beyond the representation of the semantic content, should have adequate inferential properties. More precisely, we want to be able to use the formal representations we build in order to draw inferences whose results have to be in accordance with the results of natural reasoning made by human beings.

In this paper, we will first recall the main characteristics of the overall representation system of spatial expressions' semantics already proposed and focus on the orientational part. We will then introduce new tools for dealing with orientation in internal and external localisation processes.

\section{2- A 3 level system for the representation of space in language}

This section is a summary of what is presented in (Aurnague \& Vieu 93). Contrary to (Leech 69) and to a certain extent to (Miller \& Johnson-Laird 76), several linguists showed that a purely geometrical representation of the semantics of spatial prepositions is not appropriate (Herskovits 86) (Lang 90) (Talmy 83) (Vandeloise 86a). For instance, if sur (on) was represented only in terms of contact, we could not differentiate between the sentences:

La tapisserie est sur le mur

(The wall-paper is on the wall)

L'armoire est contre le mur

(The cupboard is against the wall) 
In this example, the geometrical approach does not take into account the functional component of the semantics of the preposition sur (on) corresponding to the notion of "support". More generally, the functional aspects of the relations and entities involved in spatial expressions play a major part in the semantics of spatial markers. However, we do not claim, as Vandeloise does, that functional notions alone can fully explain spatial semantics and we think that geometrical and functional data need to be articulated.

As in any field of natural language, pragmatic phenomena influence the semantics of spatial markers. For instance, a book is usually said to be on the table, even though the book is on another book and thus not in contact with the table. Because the relation between the two books is not relevant, one can "forget" about it and think of the book directly in relation to the table. In (Herskovits 86), A. Herskovits shows that, if instead of two books one on top of the other, it was a lid on a tea-pot, it would be impossible to "infer" that the lid is on the table. In this case, being on the tea-pot, the lid fulfils its function with respect to the tea-pot and this fact cannot be "forgotten". Several pragmatic principles can be isolated which are in fact instances of more general ones governing any kind of discourse or dialogue such as Grice's principles of cooperativity (Grice 75). For instance, the underlying pragmatic principles involved in the previous example are the maxims of relevance and quantity. If a fact is relevant (in this case the lid is on the pot), expressing a less precise fact (in this case the lid is on the table) somehow implies that the precise fact is not verified in the given situation.

According to these remarks and to several others of the same kind, we have proposed to analyse and represent the meaning of spatial expressions by means of a three-level system which takes into account geometrical, functional and pragmatic information.

\section{1- The geometrical level}

At the geometrical level, we deal with the topological notions of inclusion, contact, boundary, etc., and with concepts related to projective geometry such as straight line, distance, order on a straight line, etc.

At this level, we handle the spatial referents of the entities, that is, the space portions determined by their matter at a precise moment. These elements are also called here individuals.

The actual use of prepositions like sur (on) and dans (in) which allow us to situate an entity called "trajector" with respect to another entity called "landmark" shows the relational nature of the structures handled in language, as opposed to the absolute spaces used in robotics (where entities are localised by means of coordinates). Moreover, two properties of these absolute spaces seem to contradict the structures of space in natural language. Whereas, in a coordinate system, the positions of every entity need to be known exactly, the spatial information expressed in a text is often partial and imprecise. Another problem arises from the fact that the 
variable granularity of space in language (for instance, the same entity can be considered at one time as a point and later as a volume) is not compatible with the discrete structure characterising an implementable coordinate system, where the minimum units are defined $a$ priori. So, knowledge representation at the geometrical level will be achieved through a relational structure rather than through a coordinate system. Consequently, the spatial referent of the entities will be viewed as primitive elements and not, for instance, as sets of points within a Euclidean space. Space is therefore built from the text and not assumed beforehand (this is similar to the construction of time proposed in (Kamp 1979)).

In order to reflect these characteristics of linguistic space, topological data is represented in our system by means of B.L. Clarke's individual calculus (Clarke 81) (Clarke 85) (Randell \& Cohn 89) that we modified and completed so as to take into account some important spatial concepts in language. This calculus, which is based on the sole primitive relation of connection between two individuals $(\mathrm{C}(\mathrm{x}, \mathrm{y}))$, is used to define some mereological, as well as Boolean and topological, operators.

As regards mereology, we can mention inclusion, overlapping and external connection between two individuals. In the Boolean part of the calculus, operators such as sum, product and complement are introduced. As for topological aspects, the interior of an individual, its closure and the properties of being closed and open can be defined.

Individual calculus based on connection is not sufficient, as it is, to deal with some problems related to the semantics of space in language. Consequently, we extended this theory to express some fundamental spatial notions such as limits and contact. We introduced three types of limit relations (lim1, $\lim 2$, lim3) through which surface-, line- or point-like individuals can be differentiated. These limit concepts are very important for the formalisation of ILNs like dessus (top extremity), bord (edge), angle (corner), etc. (Aurnague 91). We also added to the strong contact notion represented by external connection (the individuals in contact are assumed to share part of their boundaries), a notion of weak contact (the individuals are not connected although they touch) which seems to better match common sense. Let us suggest that contact plays a great role in the semantics of the relation sur (on).

At a second stage, spatial points are constructed as sets of individuals by method akin to the maximal filters construction for defining time instants in a theory of time based on events or periods (Kamp 79) (van Benthem 83). To avoid inconsistencies, the construction of "interior points" (the individuals of these points overlap two by two) needs to be differentiated from the construction of "boundary points" (there exist two externally connected individuals in these points); it is one essential aspect of our modification of Clarke's theory (Vieu 91). Having built the "points" and introduced two new primitive relations between points "is situated between" noted T and "is closer to" noted K (adapted from (van Benthem 83)), we define the notions of straight line (maximal set of points satisfying three by three the relation "is situated between"), equidistance, perpendiculars (two lines are perpendicular if in each line there exist two points such that the two points of one line are equidistant to each point of the other), parallels, etc. 
As already mentioned, at the geometrical level, not only do we take into account topological data, but we also integrate some important concepts from projective geometry. We associate a system of abstract (not oriented) axes and directions with the spatial referent of every entity and we locate the different portions with respect to the whole entity by "projecting" them on these axes. It should be made clear that an important assumption of our study is based on the delimitations of the universe of spatial entities that we describe and process (essentially with respect to their shape). For the analysis of ILNs, we had to restrict the research field of spatial entities to solid, undeformable and connected objects that also have a "normal usefulness". This is why we deal here with a class of individuals whose shape is roughly parallelepipedic, cylindrical or spherical. However, we think that these methodological restrictions are quite reasonable because the mental encoding of the entities involved in spatial relations seems to call for a very simple specification of their shape (Landau \& Jackendoff 93) (Talmy 83).

We can conclude the presentation of this level by saying that we obtained a complete relational geometry.

\section{2- The functional level}

At this level, we deal with properties linked to the entities themselves and therefore we handle variables representing entities and not mere pieces of space. We use the "function" stref (spatio-temporal referent) in order to associate an entity with the spatio-temporal individual it determines throughout its "life"2.

One of the most important processes which takes place on the functional level concerns orientation. In the same way as we restricted the type of entity processed by the system, we introduce some constraints on orientations. First, the texts studied are "instantaneous" in the sense that the entities described as well as the speaker do not change position with respect to one another. Moreover, we assume that an entity is oriented by a single speaker. As stated before, only abstract directions are handled in the geometrical module. The orientation process, which is greatly conditioned by functional features, consists in mapping an abstract orientation onto a concrete one.

Apart from the notion of orientation, we introduce at the functional level some concepts belonging to "naive physics" (Hayes 85) such as support and containment. As shown in section 2, support is essential in sur's semantics: an object hanging above a table, touching it, is not sur la table (on the table). Containment which plays a great part in the determination of natural inside can be described as the restriction of some potential movements of the contents.

At this level, we distinguish three types of entities: objects (as in all the examples above), locations (countries, cities, gardens...) and non-material "space portions" (as insides of objects, holes, cracks...). Using those categories and a lattice structure for representing plural entities, we define 6 types of part-whole relations which play a great part in some uses of dans (in) 
(Vieu 91a) (Vieu 91b).

Thanks to these tools, we introduce some formal definitions for the lexemes we study, that is to say, for 10 ILNs as well as for the prepositions sur (on) and dans (in). According to our methodological choices, we check whether the definitions we give in our system allow inferences in accordance with natural "deductions".

\section{3- The pragmatic level}

Some pragmatic principles act on the semantics obtained at the previous levels in a significant way. On top of functional knowledge, they use world knowledge (in particular, knowledge of typical situations) and information about context. The principles we consider here may be seen as the instanciation of more general ones (such as Gricean cooperativity principles (Grice 75)) in the spatial domain.

First, pragmatic principles allow one to deduce, in some cases, more information than is really present in the text and is represented on the first two levels (so we need a non-monotonic logic on this level). For instance, the sentence Marie est dans la voiture (Mary is in the car) is generally understood as Mary is in the passenger space, discarding at the same time the alternative Mary is in the boot.

Second, they may rule out some expressions (for example, expressions inferred at the previous levels) because, even though their "crude" semantics is verified by the system and in the model, they cannot be uttered, since using the first process mentioned, these expressions would be regarded as conveying information contradictory with what is known. For instance, if we know that Marie est dans le coffre de la voiture 'Mary is in the car's boot' is true, then Marie est dans la voiture 'Mary is in the car' is not false, and yet, in general we cannot answer to where is Mary? with the latter sentence, for in most contexts, it is interpreted as Mary is in the passenger space.

A "fixation principle" underlies the examples cited above. This principle, first introduced in (Vandeloise 86a) expresses the fact that the typical use of an object "fixes" some of its characteristics. For instance, the front and the back of a car are "fixed" by the usual -not the actual- direction of its motion; indeed, many intrinsic orientations are determined this way. Several other principles may be found.

Third, we must mention the pragmatic phenomenon that enables us to loosen some conditions of the semantic definitions. This phenomenon was illustrated in the previous example of the books on the table which involved the maxim of relevance.

\section{4- Focus on orientation}

Let us go back to the way the orientational process was defined in the formal system we presented up to now. We said that the spatial referent of every entity is linked to a system of 
abstract orthogonal axes and, as we will see, this is not a very accurate representation of what really takes place.

In fact, a detailed study of orientation shows that an intrinsic orientation follows from the internal properties of an entity, in particular its shape but also its function (Bierwisch \& Lang 89) (Lang 90) (Vandeloise 86b). Consequently, the axes or straight lines arising in such an intrinsic orientation are linked to the entity itself and not just to its spatial referent. This is the case of a TV or a house which both have intrinsic vertical and frontal orientations. Intrinsically oriented entities can be classified according to the way this orientation arises. For example, (Bierwisch \& Lang 89) introduces a subcategorization of vertical intrinsic orientation into three classes. In that analysis, fixed orientation occurs when entities have a fixed orientation with respect to the earth's surface (mountains, rivers), whereas canonical orientation applies to situations calling for a normal position with respect to the vertical (TVs, desks), and inherent orientation occurs when vertical orientation comes from inherent properties of the entity (books, pictures).

In the case of a contextual process, orientation is the result of the interaction between the entity involved and another entity in the context. This means that the relevant axes in a contextual orientation derive from the interaction between these two entities. For instance, such an orientation occurs when one designates the front of a tree situated in front of a tent (in this case, the front part of the tree is the part which faces the entrance of the tent). In the framework of this study, we only consider a particular case of contextual orientation, namely the deictic one, in which the orienting entity is the speaker. However, interpretations relying on vertical contextual orientation (which is given by gravity) will be formalised because, very often, vertical deictic uses are restricted to situations where the speaker is standing up.

So, if we wanted to give a very accurate account of the orientational process as it really occurs, we would have to associate predefined axes only to intrinsically oriented entities, whereas for a deictic orientation the axes would be defined by taking into account the interaction between the oriented entity and the speaker.

However, this is not the case in the formalism already proposed, even though we could determine whether we are faced with a deictic or intrinsic case. First and as we indicated above, every entity has (at the geometrical level) a predefined system of abstract axes associated with it. Second, although the formalism mentions elements which entail the association of an abstract direction with a concrete one (in an intrinsic case this process is triggered by the entity itself, whereas in the deictic one it relies on another element of the context, the speaker), this complex functional process is not described in details for each case $\mathrm{e}^{3}$.

According to these remarks, our new orientation formalism has to fulfil two main points. First of all, it has to grasp how the axes derive from the function of the entities and the shape of their spatial referents. Concerning this point, it can be underlined that giving an intrinsic orientation to an entity in a determined direction amounts to saying that for "functional 
reasons" a particular portion of this entity constitutes an extremity in this direction (e.g.: usually the neck of a bottle is up).

A second requirement for the new formalism relies on the need to use the same orientational tool for internal (ILNs), as well as for external localisations (e.g.: devant (in front of), derrière (behind), au-dessus de (above), au-dessous de (below) $)^{4}$.

The main reason for such a requirement is that, from an inferential point of view, we want to be able to combine formal definitions of external and internal markers and to derive calculations from these combinations. Another reason would be that, from linguistic and psychological points of view, the orientational mechanisms involved in internal and external localisation seem to be very similar.

\section{3- Analysis and formalisation of orientational process}

Having presented the main characteristics of our system for the representation of spatial entities and relations, we are now going to describe the new tools we introduce in order to deal with orientation. We will detail the formalisms operating at each level of the system.

\section{1- The geometrical level}

At the geometrical level we complete our ontology by introducing the basic concept of direction. Directions have already been used in various works in the field of Qualitative Physics (Davis 89) (Frank 92) (Freksa 93) or in semantic studies intended, for example, to handle the spatial information contained in car accident reports (Jayez 92).

A direction is viewed here as a primitive element which can be linked to ordered pairs of points by the following axiom, $d(\alpha, \beta)$ being a new primitive function giving the direction determined by two points $\alpha$ and $\beta$ and ND a relation expressing the notion of null distance (Aurnague \& Vieu 93):

$\mathrm{A} 1 \forall \alpha, \beta(\mathrm{PT}(\alpha) \wedge \mathrm{PT}(\beta) \wedge \neg \mathrm{ND}(\alpha, \beta)) \rightarrow \exists \mathrm{D} \mathrm{d}(\alpha, \beta)=\mathrm{D}$

Henceforth, directions will be denoted by uppercase characters so as to differentiate them from individuals and entities which are noted in lowercase.

Another axiom indicates that symmetrically ordered pairs of points determine opposed directions (the opposite operator "-" being defined below (Def1)):

A2 $\forall \alpha, \beta(\operatorname{Pt}(\alpha) \wedge \operatorname{Pt}(\beta)) \rightarrow(\mathrm{d}(\alpha, \beta)=\mathrm{D} \leftrightarrow \mathrm{d}(\beta, \alpha)=-\mathrm{D})$

We introduce a primitive relation between directions $\mathrm{Kd}(\mathrm{D} 1, \mathrm{D} 2, \mathrm{D} 3)$ which expresses that "D1 is closer to D2 than to D3" (in terms of angular values). Such a relation, similar to the primitive $\mathrm{K}$ expressing relative distance between points (axiomatized in (van Benthem 83)), is 
irreflexive and transitive (and thus asymmetric):

A3 $\forall \mathrm{D} 1, \mathrm{D} 2 \neg \mathrm{Kd}(\mathrm{D} 1, \mathrm{D} 2, \mathrm{D} 2)$

A4 $\forall$ D1,D2,D3 $(\mathrm{Kd}(\mathrm{D} 1, \mathrm{D} 2, \mathrm{D} 3) \wedge \mathrm{Kd}(\mathrm{D} 1, \mathrm{D} 3, \mathrm{D} 4)) \rightarrow \mathrm{Kd}(\mathrm{D} 1, \mathrm{D} 2, \mathrm{D} 4)$

As in the case of the primitive $\mathrm{K}$ between points, a second type of transitivity can be stated: $\mathrm{A} 5 \forall \mathrm{D} 1, \mathrm{D} 2, \mathrm{D} 3(\mathrm{Kd}(\mathrm{D} 1, \mathrm{D} 2, \mathrm{D} 3) \wedge \mathrm{Kd}(\mathrm{D} 3, \mathrm{D} 1, \mathrm{D} 2)) \rightarrow \mathrm{Kd}(\mathrm{D} 2, \mathrm{D} 1, \mathrm{D} 3)$

The primitive relation $\mathrm{Kd}$ allows us to characterise notions of opposite and orthogonal directions. The opposite of a direction is the direction which is the farthest from it, whereas a direction orthogonal to a given one is situated at an equal distance from this direction and its opposite (this last notion is defined in a set theoretical way):

Def1 -(D1,D2) $\equiv_{\text {def }} \forall$ D3 D3 $\neq$ D2 $\rightarrow$ Kd(D1,D3,D2)

Def2 Ortho(D1) $=_{\text {def }}\{\mathrm{D} 2:-\mathrm{D} 1=\mathrm{D} 3 \wedge \neg \mathrm{Kd}(\mathrm{D} 2, \mathrm{D} 1, \mathrm{D} 3) \wedge \neg \mathrm{Kd}(\mathrm{D} 2, \mathrm{D} 3, \mathrm{D} 1)\}$

Let us indicate that a particular axiom ensures the existence of the opposite of any direction:

A6 $\forall \mathrm{D} 1 \exists \mathrm{D} 2(\forall \mathrm{D} 3 \mathrm{D} 3 \neq \mathrm{D} 2 \rightarrow \mathrm{Kd}(\mathrm{D} 1, \mathrm{D} 3, \mathrm{D} 2))$.

From A6 and the fact that the opposite of a direction is unique (which can be proved using A6 and asymmetry), it follows that the relation "-" can be characterised as a function. Consequently, we will use the operator "-" as a function rather than as a simple relation, -D denoting the opposite direction of a direction $\mathrm{D}$.

We can also define the median of two directions and a kind of sum or composite of directions. The median of two distinct directions corresponds to the set of directions which are equidistant between these two directions. The sum of two directions is a subset of the median set constituted by the directions which are the nearest from these two directions (this set is a singleton for non opposed directions and its element corresponds to the median which is coplanar with the two directions, whereas for opposed directions it has two elements in 2D space and it corresponds to a whole plane in $3 \mathrm{D}$ space). We give below the set theoretical definitions characterising medians and sums as well as a linearity axiom:

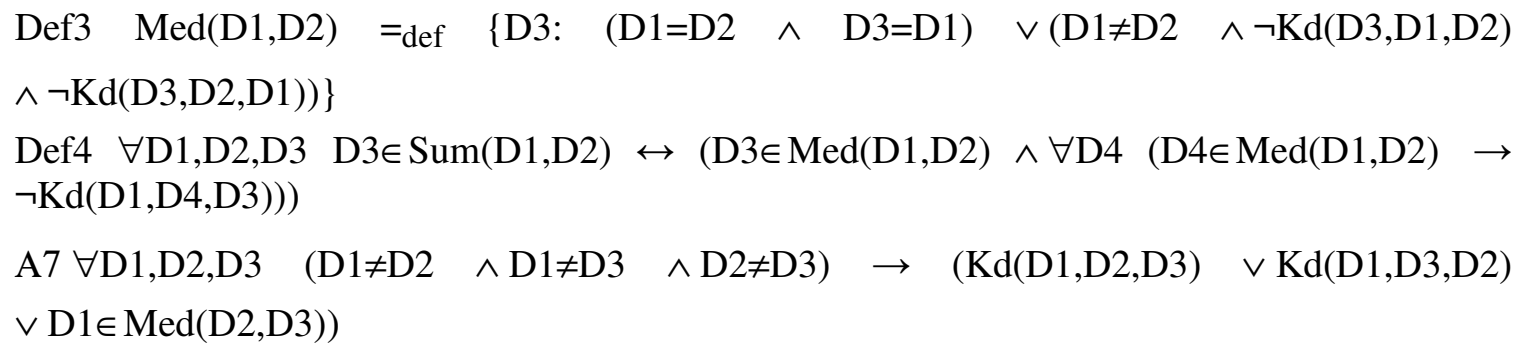

By means of the following two axioms we express the reflection or circular aspect of directions:

A8 $\forall$ D1,D2,D3 Kd(D1,D2,D3) $\leftrightarrow \mathrm{Kd}(\mathrm{D} 1,-\mathrm{D} 3,-\mathrm{D} 2)$

A9 $\forall$ D1,D2,D3 Kd(D1,D2,D3) $\leftrightarrow$ Kd(-D1,-D2,-D3) 
Finally, we state a kind of transitivity between medians and we express the relation of a direction D with respect to two directions D2 and D3 in terms of the sum of these directions: $\mathrm{A} 10 \forall \mathrm{D}, \mathrm{D} 1, \mathrm{D} 2, \mathrm{D} 3(\mathrm{D} \in \operatorname{Med}(\mathrm{D} 1, \mathrm{D} 2) \wedge \mathrm{D} \in \operatorname{Med}(\mathrm{D} 2, \mathrm{D} 3) \wedge \mathrm{D} 1 \neq \mathrm{D} 3) \rightarrow \mathrm{D} \in \operatorname{Med}(\mathrm{D} 1, \mathrm{D} 3)$ A11 $\forall$ D,D1,D2,D3 $(K d(D, D 2, D 3) \wedge$ D1 $\in$ Sum(D2,D3) $) \rightarrow(K d(D 3, D 1, D) \wedge K d(-D 2,-D 1, D))$

The theory based on this primitive $\mathrm{Kd}$ includes other definitions and axioms concerning, among other things, extensionality and coplanar directions. Although these notions should be of great importance for a complete geometry on orientation, we do not introduce them here because they are not relevant to the semantics of the spatial relations we are dealing with in this paper. Several theorems can be proved from the set of definitions and axioms set out below, in particular with regard to orthogonality ${ }^{5}$ :

$\mathrm{T} 1 \forall \mathrm{D} 1, \mathrm{D} 2 \mathrm{D} 1 \neq \mathrm{D} 2 \rightarrow \mathrm{Kd}(-\mathrm{D} 1, \mathrm{D} 2, \mathrm{D} 1)$

For every direction D2 different from D1, -D1 is closer to D2 than to D1

$\mathrm{T} 2 \forall \mathrm{D}-(-\mathrm{D})=\mathrm{D}$

Idempotency of -

$\mathrm{T} 3 \forall \mathrm{D}, \mathrm{D} 1, \mathrm{D} 2, \mathrm{D} 3 \mathrm{D} 1 \in \mathrm{Med}(\mathrm{D} 2, \mathrm{D} 3) \wedge \mathrm{Kd}(\mathrm{D} 1, \mathrm{D} 2, \mathrm{D}) \rightarrow \mathrm{Kd}(\mathrm{D} 1, \mathrm{D} 3, \mathrm{D})$

If $\mathrm{D} 1$ is the median of D2 and D3 and D1 is closer to D2 than to D it follows that D1

$\mathrm{T} 4 \forall \mathrm{D} 1, \mathrm{D} 2, \mathrm{D} 3 \mathrm{D} 1 \in \mathrm{Med}(\mathrm{D} 2, \mathrm{D} 3) \wedge \mathrm{D} 1 \in \mathrm{Ortho}(\mathrm{D} 2) \rightarrow \mathrm{D} 1 \in \mathrm{Ortho}(\mathrm{D} 3)$

A8 A10 Def2 Def3 T2 T3

If D1 is the median of D2 and D3 and D1 is orthogonal to D2 then D1 is orthogonal to D3

T5 $\forall$ D1,D2 D1 $\in$ Ortho(D2) $\leftrightarrow-\mathrm{D} 1 \in$ Ortho(D2)

A9 Def2

Saying that D1 is orthogonal to D2 is equivalent to saying that -D1 is orthogonal to D2

T6 $\forall$ D,D1 (D1 $\in$ Ortho(D) $\rightarrow \forall$ D2 (Kd(D,D2,-D2) $\leftrightarrow$ Kd(D,D2,D1))

A3 A4 A5 A7 A8 Def2 Def3 T2 T4 T5

If $\mathrm{D} 1$ is orthogonal to $\mathrm{D}$, saying that $\mathrm{D}$ is closer to $\mathrm{D} 2$ than to $-\mathrm{D} 2$ is equivalent to saying that $\mathrm{D}$ is closer to $\mathrm{D} 2$ than to D1

$\mathrm{T} 7 \forall \mathrm{D} 1, \mathrm{D} 2 \mathrm{Kd}(\mathrm{D} 1, \mathrm{D} 2,-\mathrm{D} 2) \leftrightarrow \mathrm{Kd}(\mathrm{D} 2, \mathrm{D} 1,-\mathrm{D} 1)$

A3 A4 A7 A11 Def2 Def3 Def4 T6

Saying that D1 is closer to D2 than to -D2 is equivalent to saying that D2 is closer to D1 than to -D1

T8 $\forall$ D1,D2 D1 $\in$ Ortho(D2) $\leftrightarrow$ D2 $\in$ Ortho(D1)

Symmetry of orthogonality

A more complete presentation of this theory on orientations detailing the different deductions which can be drawn will be proposed in (Asher, Aurnague \& Vieu forthcoming). Let us indicate that this axiomatics needs to be studied further in order to minimise the number of axioms and to verify its properties from a model theoretical point of view (in particular soundness).

To formalise correctly the orientational process, we also have to introduce at the geometric level a set of thirteen predicates constituting an extension of Allen's relations ${ }^{6}$ (R) (Allen 84). Each formula $\mathrm{R}(\mathrm{x}, \mathrm{y}, \mathrm{D})$ indicates the configuration between the maximum intervals filled by the individuals $\mathrm{x}$ and $\mathrm{y}$ in the direction $\mathrm{D}^{7}$. Besides the classical axioms related to Allen's relations we introduce here a postulate stating that for every pair of connected individuals $\mathrm{x}$ and $\mathrm{y}$ and every direction $\mathrm{D}$, one of the relations $\mathrm{m}, \mathrm{o}, \mathrm{s}, \mathrm{d}, \mathrm{f}$ or $=$ stands between them :

A12 $\forall \mathrm{x}, \mathrm{y}, \mathrm{D} \mathrm{C}(\mathrm{x}, \mathrm{y}) \rightarrow \operatorname{mosdf}=\mathrm{miO}_{\mathrm{i}} \mathrm{sid}_{\mathrm{i}} \mathrm{f}_{\mathrm{i}}(\mathrm{x}, \mathrm{y}, \mathrm{D})^{8}$

We state that $\mathrm{y}$ is an extremity of $\mathrm{x}$ in a direction $\mathrm{D}$ if $\mathrm{y}$ is a limit of $\mathrm{x}$ (as underlined above, the concept of limit has been already formalised at the geometric level of our representation 
system) and furthermore if every individual included in $\mathrm{x}$ (and not included in $\mathrm{y}$ ) precedes or meets $\mathrm{y}$ in this direction $\mathrm{D}$ :

$\operatorname{Def5} \operatorname{Ext}(\mathrm{y}, \mathrm{x}, \mathrm{D}) \equiv \equiv_{\operatorname{def}} \operatorname{Lim} 1(\mathrm{y}, \mathrm{x}) \wedge \forall \mathrm{v}((\mathrm{P}(\mathrm{v}, \mathrm{x}) \wedge \neg \mathrm{P}(\mathrm{v}, \mathrm{y})) \rightarrow<\mathrm{m}(\mathrm{v}, \mathrm{y}, \mathrm{D}))$

It can be observed that, in some cases, for two given individuals $\mathrm{x}$ and $\mathrm{y}$ (for instance when we are faced with the vertex $y$ of a triangle $\mathrm{x}$ ) several directions may verify this relation. Generally, this occurs when a tangent to the surface cannot be associated with some particular point.

If we wanted a unique direction to be selected, we would have to introduce more constraints or conditions. That is exactly what we do by introducing a relation "Exts", which indicates that $\mathrm{y}$ is an extremity of $\mathrm{x}$ in the direction $\mathrm{D}$, and $\mathrm{z}$ an extremity (of a part $\mathrm{u}$ of $\mathrm{x}$ ) in the opposite direction:

Def6 Exts $(y, z, x, D) \equiv{ }_{\operatorname{def}} \operatorname{Ext}(y, x, D) \wedge \exists u(P(u, x) \wedge P(y, u) \wedge \operatorname{Ext}(z, u,-D) \wedge$ Salient $(z, x) \wedge(\neg \exists v$ $\operatorname{Point}(\mathrm{z}, \mathrm{v}) \vee \neg \exists \mathrm{v}$ Point $(\mathrm{y}, \mathrm{v})))$

In this definition the predicate "Salient" accounts for the visual and cognitive processes that lead us to select a geometrically salient individual $\mathrm{z}$ in the individual $\mathrm{x}$. A further specification of this phenomenon requires a precise study of the underlying processes. The remainder of the definition ensures that this individual $\mathrm{z}$ constitutes an extremity in the direction -D and that one of these extremities is not punctual.

Going back to the case of the triangle, such an additional condition allows us (by taking into account the orthogonal direction at the base of the triangle) to select a unique direction among the first set of directions.

\section{2- Functional level}

\subsection{1- Intrinsic orientation}

Using the different tools we have built up to now at the geometrical level, and taking into account the properties of the entities themselves, we can tackle the formalisation of the orientational process. In this paper, we consider first the intrinsic case, examining only vertical and frontal orientation, that is, leaving aside the lateral case; the deictic case, as well as all contextual cases, is eventually grounded on the intrinsic orientation of some entity. Consequently, the latter is studied in the definition section (§3.2.2).

Basing our analysis on the remark we made about the importance of the extremity notion for intrinsic orientation, we introduce a new partial function mapping an extremity y of an entity $\mathrm{x}$ (and an extremity $\mathrm{z}$ of a portion of $\mathrm{x}$ ) onto the corresponding direction $\mathrm{D}$ :

Def7 $\forall \mathrm{x}, \mathrm{y}, \mathrm{z}, \mathrm{D} \operatorname{dir}-\operatorname{ext}(\mathrm{y}, \mathrm{z}, \mathrm{x})=\mathrm{D} \leftrightarrow(\operatorname{Part}(\mathrm{y}, \mathrm{x}) \wedge \operatorname{Part}(\mathrm{z}, \mathrm{x}) \wedge \operatorname{Exts}(\operatorname{stref}(\mathrm{y}), \operatorname{stref}(\mathrm{z}), \operatorname{stref}(\mathrm{x}), \mathrm{D}))$ 
Henceforth we will say that such a direction is generated by the extremities $\mathrm{y}$ and $\mathrm{z}$ of $\mathrm{x}$.

The above axiom which directly handles entities and not simple portions of space ${ }^{9}$ relies on the geometric relation "Exts" (indicating that the individual stref(y) constitutes an extremity of stref(x) in a direction) as well as on the part-whole relations between entities already defined in our system.

Starting with the vertical intrinsic orientation, a particular direction of an entity can be considered as its upper intrinsic direction if, in a canonical position, this direction coincides with the gravitational upper direction. We express these conditions by means of the following definition $^{10}$ :

Def8 Orient-haut(D,x) $\equiv \equiv_{\text {def }} \quad \exists y, z \quad(\operatorname{dir}-\operatorname{ext}(\mathrm{y}, \mathrm{z}, \mathrm{x})=\mathrm{D} \wedge$ Can-Use(x) $\wedge(\operatorname{In}-U \operatorname{se}(\mathrm{x})>\operatorname{dir}-$ $\operatorname{ext}(\mathrm{y}, \mathrm{z}, \mathrm{x})=$ haut-grav $))$

In this definition, the predicate "Can-Use" ensures that the entity $\mathrm{x}$ has a canonical use. The predicate "In-Use" together with the non-monotonic implication ( $>$ denoting an implicature) allows us to restrict the coincidence of the directions to "normal" (canonical) uses of $\mathrm{x}$. We think that the non-monotonic logic proposed in (Asher \& Morreau 91) could be a good framework for handling such information.

A similar formula specifies what is a lower intrinsic orientation, and a biconditional links it to the previous upper orientation :

Def9 Orient-bas(D,x) $\equiv_{\text {def }} \quad \exists y, z \quad(\operatorname{dir}-\operatorname{ext}(\mathrm{y}, \mathrm{z}, \mathrm{x})=\mathrm{D} \quad \wedge$ Can-Use(x) $\wedge(\operatorname{In}-$ Use(x) $>$ dir$\operatorname{ext}(\mathrm{y}, \mathrm{z}, \mathrm{x})=$ bas-grav $))$

A18 haut-grav $\leftrightarrow$ - (bas-grav)

The processing of frontal orientation calls for more complex mechanisms that mirror more complex phenomena. We thus distinguish three cases, which, as we shall see, are not mutually exclusive.

The first case occurs when the frontal orientation of an entity $\mathrm{x}$ is induced by what Vandeloise calls the "general orientation" of $x$ (Vandeloise 86a), which depends on various factors such as the direction of motion, the arrangement of the perception apparatus, etc. So, we first state that a given direction of an entity $\mathrm{x}$ may be considered as a front direction of type 1 if that direction of $\mathrm{x}$ coincides with its general orientation:

Def10 Orient-avant $1(\mathrm{D}, \mathrm{x}) \equiv_{\mathrm{def}} \exists \mathrm{y}, \mathrm{z} \operatorname{dir}-\operatorname{ext}(\mathrm{y}, \mathrm{z}, \mathrm{x})=\mathrm{D} \wedge$ Orient-gen(x,D)

We find in this category human beings, animals, arrows, but also cars and vehicles in general $^{11}$.

The second kind of frontal orientation covers all of the entities whose frontal direction coincides, in canonical use, with the frontal direction of the user. So, by means of this second rule, we state that a specific direction of an entity $\mathrm{x}$ constitutes a front direction of type 2 if the front direction of every entity using $\mathrm{x}$ in a canonical way coincides with this direction of $\mathrm{x}$ :

Def11 Orient-avant2(D,x) $\equiv_{\text {def }} \exists \mathrm{y}, \mathrm{z}\left(\operatorname{dir}-\operatorname{ext}(\mathrm{y}, \mathrm{z}, \mathrm{x})=\mathrm{D} \wedge\right.$ Can-Use(x) $\wedge \forall \mathrm{u}, \mathrm{D}^{\prime}(($ Utilise $(\mathrm{x}, \mathrm{u})$ 
$\wedge$ Orient-avant1( $\left.\left.\left.\left.\mathrm{D}^{\prime}, \mathrm{u}\right)\right)>\mathrm{D}^{\prime}=\operatorname{dir}-\operatorname{ext}(\mathrm{y}, \mathrm{z}, \mathrm{x})\right)\right)$

This second case of frontal orientation that we call tandem orientation happens with chairs, cars, clothes, etc.

The third and last rule corresponds to entities whose frontal direction is opposed, in canonical use, to the user's frontal direction (cupboards, computers, TVs, etc.):

Def12 Orient-avant3(D,x) $\equiv_{\text {def }} \exists \mathrm{y}, \mathrm{z}\left(\operatorname{dir}-\operatorname{ext}(\mathrm{y}, \mathrm{z}, \mathrm{x})=\mathrm{D} \wedge\right.$ Can-Use(x) $\wedge \forall \mathrm{u}, \mathrm{D}^{\prime}(($ Utilise $(\mathrm{x}, \mathrm{u})$ $\wedge$ Orient-avant $\left.\left.\left.1\left(\mathrm{D}^{\prime}, \mathrm{u}\right)\right)>\mathrm{D}^{\prime}=-\operatorname{dir}-\operatorname{ext}(\mathrm{y}, \mathrm{z}, \mathrm{x})\right)\right)$

Finally, we express through the following rules that every entity having an intrinsic frontal orientation falls into one of these three cases and that front and back (intrinsic) directions stand in a relation of opposition :

Def13 Orient-avant $(D, x) \equiv$ def Orient-avant $1(D, x) \vee$ Orient-avant2(D, $x) \vee \operatorname{Orient-avant} 3(D, x)$ $\forall \mathrm{x}, \mathrm{D}$ Orient-avant $(\mathrm{D}, \mathrm{x}) \leftrightarrow$ Orient-arriere(-D, $\mathrm{x})$

The formalisation of the lateral cases which is not completely worked out for the moment, is left aside in this paper. However, it can be underlined that this lateral modality calls for already more complex representations than frontal orientation does (which, as we just saw, is itself more complex than the vertical one). This property of our formal tools seems to match perfectly the observations made by psycholinguists about the acquisition and manipulation of orientation notions (Pièrart 79).

\subsection{2- Definitions}

Thanks to all of the geometrical and functional tools introduced above, we can now express the "crude" semantics of various internal and external localisation lexemes. We will especially consider the formalisation of their semantic component relative to orientation.

\subsubsection{1- Internal localisation}

Let us start with Internal Localisation Nouns (ILNs) and more precisely with the definition of the haut (top) of an entity. Intuitively, the intrinsic top corresponds to the portion of the entity situated in the pole whose direction is the intrinsic upper direction. Consequently, we state by means of the following definition, that an entity y constitutes the intrinsic top of an entity $\mathrm{x}$ if $\mathrm{y}$ is the maximal element situated in the pole of $\mathrm{x}$ whose direction is $\mathrm{D}$, and furthermore, if this direction corresponds to the intrinsic upper direction of $\mathrm{x}$ :

Def14 Haut-i(y,x,D) $\equiv_{\text {def }}$ Orient-haut(D,x) $\wedge$ In-pole(y,x,D) $\wedge \forall \mathrm{w} \quad($ In-pole $(w, x, D) \rightarrow$ $\operatorname{Part}(\mathrm{w}, \mathrm{y}))$

The direction D appearing in this predicate "Haut-i" plays a very important part for the 
distinction between intrinsic and deictic top cases. In the case of an intrinsic top this direction comes from the entity itself, whereas in a deictic situation, it is given by another element of the context (the speaker) and does not have any special relation with the entity ${ }^{12}$ :

Def15 Haut-d(y,x,D) $\equiv_{\text {def }} \exists$ s (Orient-haut(D,s) $\wedge \mathrm{s} \neq \mathrm{x} \wedge$ Speaker(s) $\wedge$ In-pole $(y, x, D) \wedge \forall$ w (In$\operatorname{pole}(\mathrm{w}, \mathrm{x}, \mathrm{D}) \rightarrow \operatorname{Part}(\mathrm{w}, \mathrm{y})))$

As we pointed out before, and in accordance with some experiments made by psychologists and psycholinguists (Carlon-Radvansky \& Irwin 93), these vertical deictic uses are much more acceptable when they coincide with vertical contextual uses, that is to say, when the intrinsic upper direction of the speaker coincides with the gravitational up. In consequence, although in this study as a whole, we do not consider contextual cases other than deictic ones, the contextual use of haut (top) seems an important configuration to describe:

Def16 Haut-c(y,x,haut-grav) $\equiv_{\text {def }}$ In-pole(y,x,haut-grav) $\wedge \forall$ w (In-pole(w,x,haut-grav) $\rightarrow$ $\operatorname{Part}(\mathrm{w}, \mathrm{y})))$

We give below the definitions corresponding to the concept of pole (and inclusion in a pole). Basically we can say that the pole $y$ of an entity $\mathrm{x}$ in a direction $\mathrm{D}$ is constituted by the portion of $\mathrm{x}$ extending from the middle of $\mathrm{x}$ to its extremity in the direction $\mathrm{D}$. These rules essentially rely on Allen's relations between the spatio-temporal referents of the previously mentioned entities (middle, extremity, etc.) in the direction D:

Def17 Pole(y,x,D) $\equiv_{\text {def }} \quad \exists$ e,m $(\operatorname{Part}(\mathrm{y}, \mathrm{x}) \wedge \quad \operatorname{Middle}(\mathrm{m}, \mathrm{x}) \wedge \operatorname{Ext}(\operatorname{stref}(\mathrm{e}), \operatorname{stref}(\mathrm{x}), \mathrm{D})$ $\wedge \mathrm{m}(\operatorname{stref}(\mathrm{m}), \operatorname{stref}(\mathrm{y}), \mathrm{D}) \wedge \mathrm{f}(\operatorname{stref}(\mathrm{e}), \operatorname{stref}(\mathrm{y}), \mathrm{D}))$

$\operatorname{Def} 18 \operatorname{In}-\operatorname{pole}(\mathrm{y}, \mathrm{x}, \mathrm{D}) \equiv_{\mathrm{def}} \exists \mathrm{u}(\operatorname{Pole}(\mathrm{u}, \mathrm{x}, \mathrm{D}) \wedge \operatorname{Part}(\mathrm{y}, \mathrm{u}))$

On the basis of our orientational tools, we can introduce similar formal representations for the ILNs bas (bottom), avant (front), arrière (back). It is also possible to specify the semantic content of ILNs such as dessus (top extremity), dessous (bottom extremity), devant (front extremity), derrière (back extremity) using the same formalisation of orientational phenomena. The only difference between the semantic definition of these lexemes and the representations associated with the ILNs haut, bas, avant, arrière, etc. is based on the topological and geometric aspects. For instance, the dessus (top extremity) of an entity is the uppermost surface (roughly) perpendicular to the upper direction and in contact with the exterior of the entity. We obviously need topological and geometric concepts here which are much more complex than the sole notion of pole in a direction. In (Aurnague 91), several definitions are introduced in order to characterise what is an external surface perpendicular to a direction D and furthermost in this direction.

\subsubsection{External localisation}

One of the goals of this study was to propose orientation tools which could be used to 
formalise the semantic content of internal as well as external localisation lexemes.

Now, we are going to show how our orientational formalism help to express the meaning of the external preposition devant (in front of). We can say that an entity y is situated (intrinsically) in front of an entity $\mathrm{x}$ if $\mathrm{y}$ is included in the space portion situated in front of $\mathrm{x}$ (that is to say the space portion delimited by means of $\mathrm{x}$ and its intrinsic frontal direction). In order to grasp such a configuration, we introduce the predicate In-sp(y,x,D) which specifies that an entity $\mathrm{y}$ is included in the space delimited by the entity $\mathrm{x}$ and the direction D. From a more formal point of view, this is expressed by stating that a relation $\mathrm{m}_{\mathrm{i}}$ or $>$ stands between the spatio-temporal referents of $\mathrm{y}$ and $\mathrm{x}$ in the direction $\mathrm{D}^{13}$ :

Def19 In-sp $(y, x, D) \equiv_{\text {def }} m_{i}>(\operatorname{stref}(y), \operatorname{stref}(x), D)$

Then we can characterise the fact that an entity y is situated intrinsically in front of an entity $\mathrm{x}$, indicating that $\mathrm{y}$ has to be contained in the space delimited by $\mathrm{x}$ and the direction $\mathrm{D}$, which in turn constitutes the intrinsic frontal direction of $\mathrm{x}$ :

Def20 Etre-devant-i(y,x,D) $\equiv_{\text {def }}$ Orient-avant $(D, x) \wedge \operatorname{In}-s p(y, x, D)$

Here again the deictic use of the preposition devant (in front of) differs from the intrinsic use in the underlying direction given by a speaker describing the scene situated in front of him: Def21 Etre-devant-d(y,x,D) $\equiv_{\text {def }} \exists \mathrm{s}$ (Orient-avant(-D,s) $\wedge \mathrm{s} \neq \mathrm{x} \wedge \mathrm{s} \neq \mathrm{y} \wedge$ Speaker(s) $\wedge$ In$\operatorname{sp}(\mathrm{y}, \mathrm{x}, \mathrm{D}) \wedge$ Etre-devant-i $(\mathrm{x}, \mathrm{s},-\mathrm{D}))$

The fact that the speaker is facing the landmark to which he gives a frontal orientation means that we consider a mirror configuration (between the orienting speaker and the landmark). This is expressed by the minus sign associated with the underlying direction of the predicate "Orient-avant". In fact, mirror deictic configurations are very frequent in French as opposed to tandem orientations which are less often used.

\subsection{3- Inferences}

As we said previously in the description of our methodological choices, we wish to obtain a semantic representation of utterances allowing us to draw inferences which have to be in accordance with the deductions made by human beings. We already showed in (Aurnague \& Vieu 93) that the inferences we can draw with the formal definitions dans (in), sur (on) as well as with ILNs such as haut (top), devant (front extremity), dessous (bottom extremity) match our commonsense intuitions. For instance from le vase est sur le dessus de l'armoire (the vase is on the top extremity of the cupboard) we can deduce that le vase est sur le haut de l'armoire (the vase is on the top of the cupboard). We will not give here the different steps of such a reasoning because it essentially relies on topological, and not on orientational, considerations (the reason is that the lexemes haut (top) and dessus (top extremity) have a similar semantic content from an orientational point of view and differ only in terms of topological aspects). 
However, we shall set out some of the inferences and calculations we can make using the semantic definitions previously proposed for the external preposition devant (in front of). Looking at two sentences in which this preposition appears, we examine the results obtained by applying transitivity to their formal representations. We split the verification into three cases according to the deictic or intrinsic nature of the relation involved in each of the two sentences we combine.

\subsubsection{1- Intrinsic-intrinsic case}

An example of an utterance made up of two intrinsic devant (in front of) prepositions is ${ }^{14}$ :

La tabouret est devant le fauteuil

(The stool is in front of the armchair)

\section{Le fauteuil est devant Max}

(The armchair is in front of Max)

Using the formal tools introduced for the preposition devant, we can give the following representation of these two sentences in which $\mathrm{t}, \mathrm{f}$ and $\mathrm{m}$ respectively denote the stool, the armchair and Max:

Etre-devant-i(t,f,d1)

Etre-devant-i(f,m,d2)

From the predicate "In-sp" appearing in the definition of "Etre-devant" we can deduce the following Allen's relations between the spatio-temporal referents of $\mathrm{t}, \mathrm{f}$ and $\mathrm{m}$ :

$$
\begin{aligned}
& m_{i}>(\operatorname{stref}(t), \operatorname{stref}(f), d 1) \\
& m_{i}>(\operatorname{stref}(f), \operatorname{stref}(m), d 2) .
\end{aligned}
$$

A very important parameter in the sense that it affects the overall deduction process concerns the identity of the directions $\mathrm{d} 1$ and $\mathrm{d} 2$ underlying the two relations "Etre-devant". If we know that these directions coincide (which is formally expressed by $\mathrm{d} 1=\mathrm{d} 2$ ) we can, on the basis of the axioms associated with Allen's relations (here we use the theorem $\forall \mathrm{x}, \mathrm{y}, \mathrm{z} \mathrm{m}_{\mathrm{i}}>(\mathrm{x}, \mathrm{y}, \mathrm{D})$ $\left.\wedge \mathrm{m}_{\mathrm{i}}>(\mathrm{y}, \mathrm{z}, \mathrm{D}) \rightarrow>(\mathrm{x}, \mathrm{z}, \mathrm{D})\right)$, deduce that $>(\operatorname{stref}(\mathrm{t}), \operatorname{stref}(\mathrm{m}), \mathrm{d} 2)$, which, in accordance with the definition of "In-sp", entails In-sp(t,m,d2). Associating this fact with the information about frontal intrinsic orientation of $\mathrm{m}$ : Orient-avant $(\mathrm{d} 2, \mathrm{~m})$ contained in the definition of Etredevant-i(f,m,d2), we obtain:

$$
\text { Etre-devant-i }(\mathrm{t}, \mathrm{m}, \mathrm{d} 2) \leftrightarrow \text { Orient-avant }(\mathrm{d} 2, \mathrm{~m}) \wedge \mathrm{In}-\mathrm{sp}(\mathrm{t}, \mathrm{m}, \mathrm{d} 2)
$$

Consequently, we succeed in calculating that le tabouret est devant Max (the stool is in front of Max) intrinsically, given the two previous sentences and the additional constraint ensuring the coincidence between the intrinsic frontal direction of the armchair and Max. The importance of this constraint is illustrated by figures 1 and 2 . In the first case, the two intrinsic 
directions coincide and le tabouret est devant Max can be uttered, whereas in the second configuration, they are different so that the previous deduction cannot be drawn. Although, for pictorial facilities, we have represented aligned entities with identical or opposed intrinsic directions, it may be noted that, in accordance with the definitions we proposed for devant (in front of), directional prepositions do not require alignment along the underlying direction ${ }^{15}$. Moreover the blocking of the inferences based on transitivity occurs every time the directions associated with the relations are different and not only when they are opposed (as illustrated in the figures).

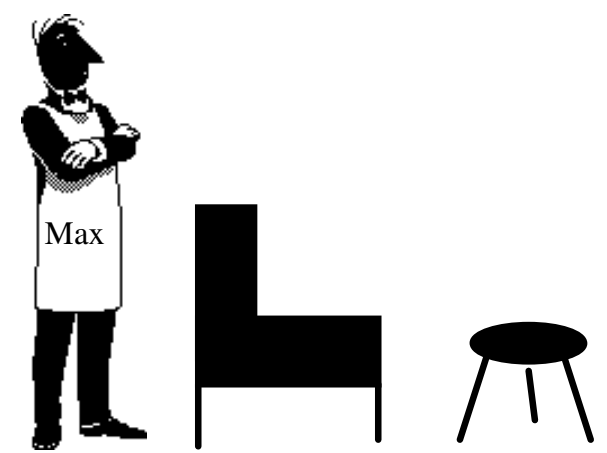

Figure 1

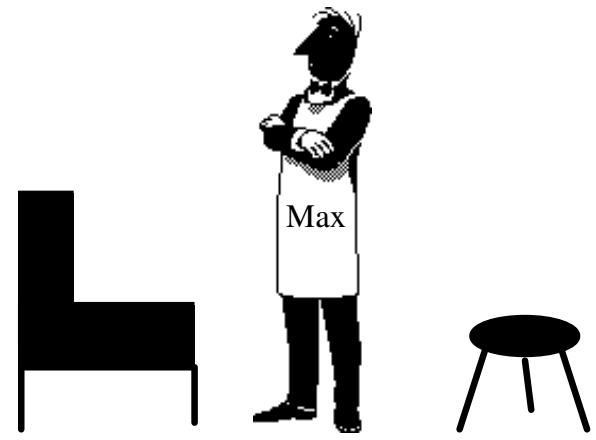

Figure 2

\subsubsection{2- Deictic-deictic case}

In an utterance such as the following, the landmarks involved in the two prepositions devant take their orientation from the speaker ${ }^{16}$ :

Le tabouret est devant la plante

(The stool is in front of the plant)

\section{La plante est devant le lampadaire}

(The plant is in front of the light)

The speaker can linguistically express the fact that this description completely depends on its spatial position with respect to the configuration by adding at the beginning of each sentence, an expression such as $v u$ d'ici (seen from here).

The following facts (based on the formal tools we described above) with $t, p$ and 1 denoting respectively the stool, the plant and the light express the semantic content of the previous sentences:

Etre-devant-d(t,p,d)

Etre-devant-d(p,1,d)

The identity of the directions underlying each relation "Etre-devant" comes directly from the hypothesis we made about the uniqueness of the speaker uttering such sentences and about 
the instantaneous character of such texts (the speaker doesn't change position). The same direction being associated with the two deictic relations "Etre-devant", we can here again calculate that In-sp(t,1,d) and finally conclude that Etre-devant- $\mathrm{d}(\mathrm{t}, 1, \mathrm{~d})$, which means that $l e$ tabouret est devant le lampadaire (the stool is in front of the light, deictically ). We do not specify all the calculation steps because they are very similar to what has been shown in the previous example.

Obviously, if the underlying directions had been different, it would not have been possible to draw such an inference. This may occur only when the spatial configuration is described from different positions or points of view in the two sentences (the same speaker occupying distinct positions at different moments or two speakers situated at distinct positions at the same moment which our work does not address). Figures 3 and 4 highlight the fact that transitive deductions work when a single speaker (Max) applies his orientation to the landmarks (the plant and the light): in this case (figure 3) the sentence le tabouret est devant le lampadaire (the stool is in front of the light, deictically ) can be inferred. On the contrary, the presence of two speakers (Max and Arthur in figure 4) describing the spatial configuration from distinct positions means that the sentence le tabouret est devant le lampadaire is neither true from Max's nor from Arthur's point of view.

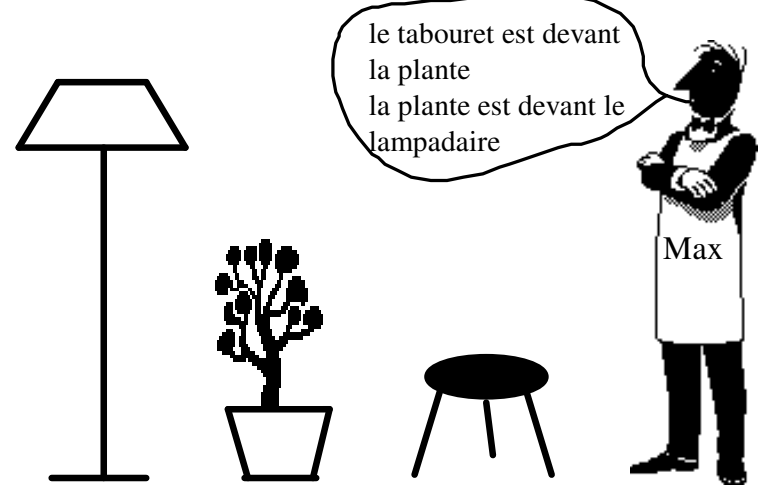

Figure 3

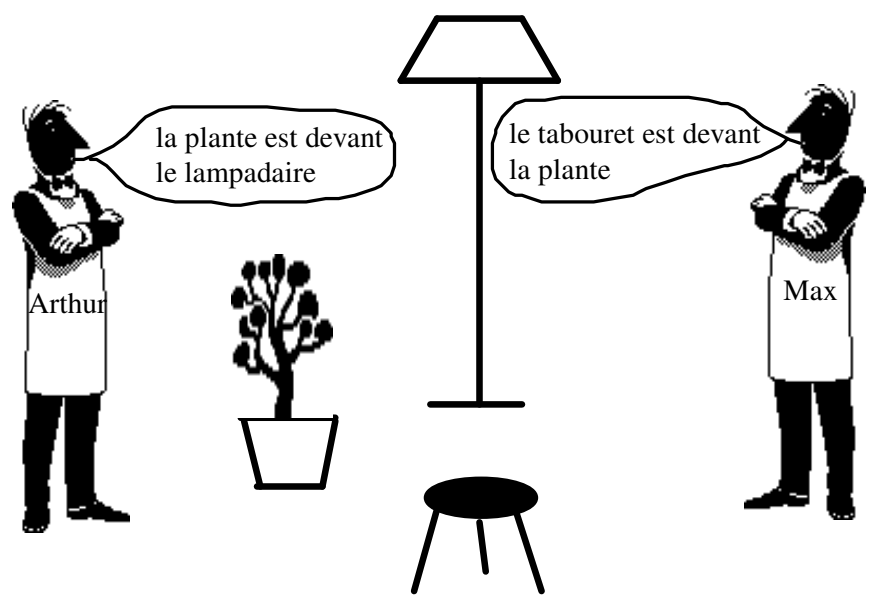

Figure 4 
Let us consider now what kind of calculation may occur if the previous spatial configuration was described by means of an utterance composed of a deictic devant combined with a deictic derrière (rather than two deictic devant):

\section{La tabouret est devant la plante}

(The stool is in front of the plant)

\section{Le lampadaire est derrière la plante}

(The light is behind the plant)

$\mathrm{t}, \mathrm{p}$ and 1 denoting here again the stool, the plant and the light, the following formulas express the semantic content of the previous sentences:

Etre-devant-d(t,p,d)

Etre-derrière-d(1,p,-d)

From the definitions of "Etre-devant" and "Etre-derrière" and the relation "In-sp" we can state the following facts in terms of extended Allen's relations:

$$
\begin{aligned}
& m_{i}>(\operatorname{stref}(t), \operatorname{stref}(p), d) \\
& m_{i}>(\operatorname{stref}(1), \operatorname{stref}(p),-d)
\end{aligned}
$$

The second expression being equivalent to $m_{i}>(\operatorname{stref}(p)$, stref(l),d $)$, transitivity axioms associated with Allen's relations allow us to deduce that $m_{i}>(\operatorname{stref}(t), \operatorname{stref}(l), d)$ which means that:

\section{In-sp(t,l,d)}

We also know, from the definition of deictic "Etre-devant" that there is a speaker $\mathrm{s}$ different from $\mathrm{t}$ and 1 (the stool and the light) who has an intrinsic front orientation corresponding to the direction $-\mathrm{d}$ :

Orient-avant(-d,s) $\wedge \mathrm{s \neq t} \wedge \mathrm{s} \neq 1 \wedge$ Speaker(s)

In order to prove Etre-devant-d(t,l,d) it remains to be stated that 1 is situated (intrinsically) in front of s or, in other words, that this speaker s faces the light to which she/he is applying her/his frontal orientation.

From the expression Etre-devant-d(t,p,d) we can deduce that the speaker s, who utters these sentences, is facing $\mathrm{p}$ :

Etre-devant-i(p,s,-d).

The predicate "In-sp" appearing in the definition of "Etre-devant-i" tells us that: $m_{i}>(\operatorname{stref}(p)$, stref(s),-d)

This relation combined with $\mathrm{m}_{\mathrm{i}}>(\operatorname{stref}(\mathrm{l}), \operatorname{stref}(\mathrm{p}),-\mathrm{d})$ (previously mentioned) entails by transitivity $m_{i}>($ stref(l), stref(s),-d) which means that In-sp(l,s,-d).

Consequently we have:

Etre-devant-i(1,s,-d) $\wedge$ Orient-avant(-d,s) $\wedge$ In-sp(1,s,-d) 
Grouping together all the facts we have stated up to now we can, as in the previous example, infer the following formal expression, which indicates to us that le tabouret est devant le lampadaire (the stool is in front of the light, deictically ):

Etre-devant-d(t,l,d) $\leftrightarrow$ Orient-avant(-d,s) $\wedge \mathrm{s} \neq \mathrm{t} \wedge \mathrm{s} \neq 1 \wedge$ Speaker(s) $\wedge$ In-sp(t,1,d) $\wedge$ Etredevant-i(1,s,-d))

These calculations show that it is possible to draw identical deductions from utterances describing a spatial configuration by means of different but semantically equivalent external relations.

\subsubsection{3- Intrinsic-deictic case}

The last case we consider here combines an intrinsic use of the relation "Etre-devant" with a deictic one:

\section{Le tabouret est devant le fauteuil}

(The stool is in front of the armchair)

\section{Le fauteuil est devant le lampadaire}

(The armchair is in front of the light)

From the formal representation of these sentences (Etre-devant-i(t,f,d1) $\wedge$ Etre-devant$\mathrm{d}(\mathrm{f}, \mathrm{l}, \mathrm{d} 2))$, and with the same kind of calculation as previously applied, we succeed in deducing that le tabouret est devant le lampadaire (the stool is in front of the light, deictically: Etredevant-d(t,1,d2)).

Once again, the whole deductive process is conditioned by the coincidence between the intrinsic frontal direction of the armchair $\mathrm{d} 1$ and the deictic frontal direction $\mathrm{d} 2$ given to the light by a speaker s. Figures 5 and 6 illustrate respectively what happens when these directions are identical and when they are not ${ }^{17}$.

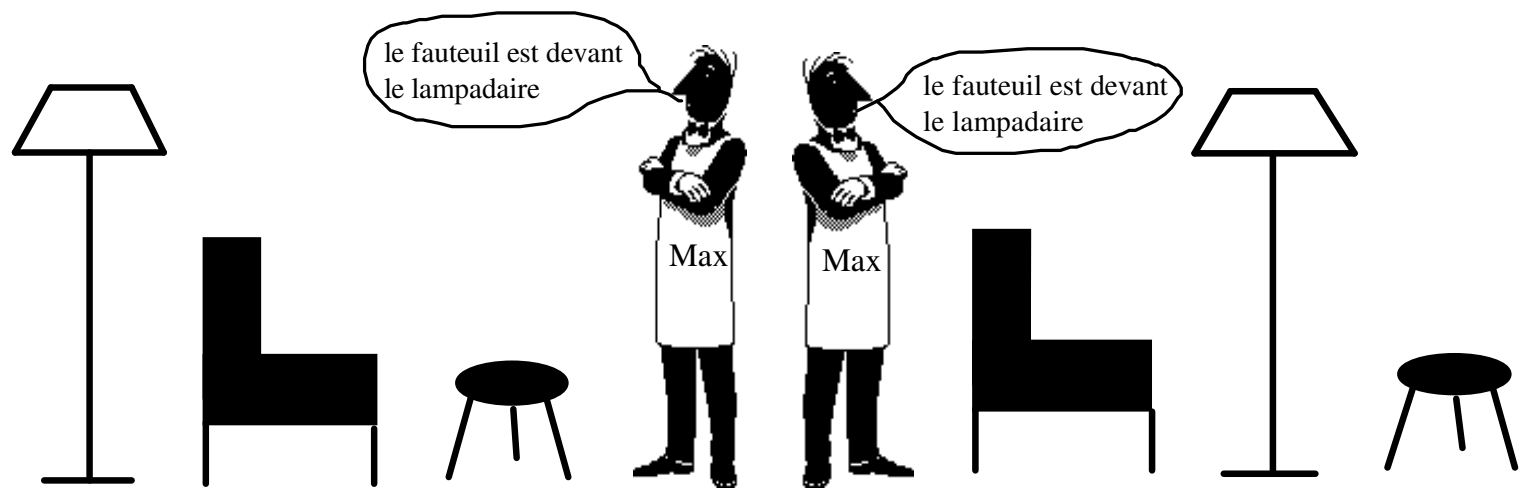

Figure 5

Figure 6 
Before finishing the presentation of the functional level, it may be mentioned that the notions of distance and relative size between the trajector and the landmark play a great part in the semantics of most spatial prepositions. Actually, the importance of these notions increases when we consider combinations of the same relation (as in the utterances above), because they constitute factors that can block the application of transitivity. However, although distance and relative size rely on geometrical tools, their part is heavily affected by contextual factors. Consequently, such phenomena have to be described and formalised at the pragmatic level.

\section{3- Pragmatic level}

As we said in the beginning, we introduce at this level the underlying principles people use in order to filter out the relations inferred wrongly, or in order to deduce more information than the discourse actually contains.

The pragmatic level modifies the semantics obtained at the functional level according to context and world knowledge. We have not yet identified and formalised all the pragmatic factors arising in orientation phenomena, but we are going to illustrate their role through the description of the axial priority principle.

As we showed at the functional level, the semantic representation of the preposition devant (in front of) constrains the positions of the trajector and the landmark with respect to the frontal axis. The definition stated that, as soon as the trajector $y$ is further on the frontal direction (associated to $\mathrm{x}$ ) than the landmark $\mathrm{x}, \mathrm{y}$ can be described as being devant (in front of ) $\mathrm{x}$ whatever its lateral position with respect to $\mathrm{x}$ is ( $\mathrm{y}$ can be on the left of/in front of/ on the right of $\mathrm{x}$ ). Nevertheless, because of the context of utterance (spatial configuration surrounding $\mathrm{x}$ and $\mathrm{y}$, intentions of the speaker, etc.), we may want to say that $y$ est exactement devant $x$ ( $\mathrm{y}$ is exactly in front of $\mathrm{x}$ ) or $y$ est davantage devant $x$ que ne l'est $z$ (y is more in front of $\mathrm{x}$ than $\mathrm{z}$ is), etc. The influence of the context can also be such that only the entities y situated exactly in front of $\mathrm{x}$ will be described as being devant $\mathrm{x}$.

By reducing the degree of freedom on the lateral axis, this pragmatic phenomenon amounts to focusing on the frontal direction; we call this "axial priority". In order to formalise the axial priority phenomenon, we introduce several definitions constraining the position of two entities $\mathrm{y}$ and $\mathrm{x}$ (representing the trajector and the landmark) with respect to a horizontal direction $\mathrm{D}^{\prime}$ which is orthogonal to the focused direction D. In fact, we consider four cases of axial priority. The first one takes into account the cases o and $\mathrm{o}_{\mathrm{i}}$ (overlapping of the extension intervals) whereas the fourth corresponds to = (equality configurations). For their part, the second and the third definitions of axial priority bring together respectively the relations $s_{i} d_{i} f_{i}$ (inclusion of $x$ in $\mathrm{y}$ along $\mathrm{D}$ ) and the converse ones $\mathrm{s}, \mathrm{d}, \mathrm{f}$ (inclusion of $\mathrm{y}$ in $\mathrm{x}$ along $\mathrm{D})^{18}$ :

Def22 Prio-axiale-horiz1 $(y, x, D) \quad \equiv_{\text {def }} \quad \exists D^{\prime} \quad\left(D^{\prime} \in\right.$ Ortho(D) $\wedge D^{\prime} \in$ Ortho(haut-grav) $\left.\wedge \mathrm{ooi}_{\mathrm{i}}\left(\operatorname{stref}(\mathrm{y}), \mathrm{stref}(\mathrm{x}), \mathrm{D}^{\prime}\right)\right)$ 
Def23 Prio-axiale-horiz2(y,x,D) $\quad \equiv_{\text {def }} \quad \exists D^{\prime} \quad\left(D^{\prime} \in\right.$ Ortho(D) $\quad \wedge D^{\prime} \in$ Ortho(haut-grav) $\left.\wedge \mathrm{sif}_{\mathrm{i}} \mathrm{d}_{\mathrm{i}}\left(\operatorname{stref}(\mathrm{y}), \operatorname{stref}(\mathrm{x}), \mathrm{D}^{\prime}\right)\right)$

Def24 Prio-axiale-horiz3(y,x,D) $\quad \equiv_{\text {def }} \quad \exists D^{\prime} \quad\left(D^{\prime} \in\right.$ Ortho(D) $\wedge D^{\prime} \in$ Ortho(haut-grav) $\left.\wedge \operatorname{sfd}\left(\operatorname{stref}(y), \operatorname{stref}(x), D^{\prime}\right)\right)$

Def26 Prio-axiale-horiz4(y,x,D) $\equiv_{\text {def }} \quad \exists D^{\prime} \quad\left(D^{\prime} \in\right.$ Ortho(D) $\wedge D^{\prime} \in$ Ortho(haut-grav) $\left.\wedge=\left(\operatorname{stref}(y), \operatorname{stref}(x), D^{\prime}\right)\right)$

Classifying in such a way the possible configurations of the entities on the lateral axis, we introduce a way of differentiating between the various entities situated devant (in front of) a given entity $\mathrm{x}$.

However, a complete formalisation of this phenomenon of axial priority would require a precise study of the contextual elements leading to these restrictions.

\section{4- Conclusion}

By focusing our research on a detailed semantic analysis, we have proposed a formalisation of orientation which allows us to represent the semantic content of spatial expressions such as le haut (the top), l'arrière (the back), être devant (to be in front), être au-dessous de (to be above), etc. We have shown that these formal definitions could be used in order to draw inferences matching the conclusions of natural (i.e. human) reasoning.

This modular representation of orientation (and more generally of space in language) constitutes, from this point of view, a real cognitive approach. It confirms the fact that the semantic analysis of spatial expressions must be justified in terms of "non linguistic structures formation" as proposed by E. Lang (Lang 90).

If we go back to the goals we set for this study in the beginning, we may point out that both have been fulfilled because our formal tool correctly grasps the differences between intrinsic and deictic orientation, and can be used furthermore to deal with internal localisation as well as external localisation. Our guess is that these properties of the formalism correctly account for some of the mechanisms underlying the cognitive processing of orientation.

Besides the points previously mentioned (notion of relative distance between trajector and landmark, pragmatic phenomena, etc.), we expect to pursue this work along two main axes. From a formal point of view, we would want to be able to define directions from individuals so as to not introduce new elements in our basic ontology. This aspect is part of a broader purpose we pursue in our group which consists in elaborating a geometry (for linguistic structures of space) based only on individuals (Asher, Aurnague \& Vieu forthcoming). We are also trying to relate the behaviour of static directions involved in localisation processes with dynamic directions underlying the expression of movement (Asher et al 94) (Asher \& Sablayrolles 95) 
(Laur 91) (Sablayrolles 93). This integration of spatial and temporal data constitutes a necessity if one wants to analyse utterances describing moving or changing configurations.

Concerning the cognitive aspects, we plan to elaborate, with various psycholinguists and psychologists, experimentations in order to test some of the hypotheses related to our formal tools or in order to highlight important properties or concepts of orientation in language (Aurnague et al 93).

Equipe de Recherche en Syntaxe et Sémantique

URA 1033 - CNRS

Maison de la Recherche

Université de Toulouse-Le Mirail

5, allées Antonio Machado

31058 Toulouse Cedex

tel : 61503607

61556091

email : aurnague@irit.fr

\section{References}

Allen, J. (1984): "Towards a general theory of action and time"; Artificial Intelligence 23, 2: 123-154.

Asher, N./Aurnague, M./Bras, M./Sablayrolles, P./Vieu, L. (1994): "Computing the spatiotemporal structure of discourse" - In Proceedings of the International Workshop on Computational Semantics 94, Tilburg.

Asher, N./Aurnague, M./Vieu, L. (forthcoming): "A relational geometry based on individuals: 1-topology, 2- distance and orientation".

Asher, N. and Morreau, M. (1991): "Commonsense Entailment : A Modal Theory of Nonmonotonic Reasoning" - In Proceedings of IJCAI-91.

Asher, N. \& Sablayrolles, P. (1995): "A typology and discourse semantics for motion verbs and spatial PP's in French"; Journal of Semantics, Special Issue on Lexical Semantics, $\mathrm{n}^{\circ} 12.1,1995$.

Aurnague, M. (1989): "Catégorisation des objets dans le langage : les noms et les adjectifs de localisation interne"; Cahiers de Grammaire n 14, UTM, Toulouse, pp 1-21.

Aurnague, M (1991): "Contribution à l'étude de la sémantique formelle de l'espace et du raisonnement spatial : la localisation interne en français, sémantique et structures inférentielles" - PhD dissertation, Université Paul Sabatier, Toulouse.

Aurnague, M. \& Vieu, L. (1993): "A three-level approach to the semantics of space" - In The semantics of prepositions: from mental processing to natural language processing, $\mathrm{C}$. Zelinsky-Wibbelt ed., Mouton de Gruyter, Berlin.

Aurnague, M./Vieu, L./Borillo, A./Borillo, M. (1993): "Connecting linguistic and visual space 
: a natural reasoning approach" - In Proceedins of ICCS'93, Donostia-San Sebastian.

van Benthem, J. (1983): The logic of time - Reidel, Dordrecht.

Bierwich, M \& Lang, E (1989): Dimensional adjectives : grammatical structure and conceptual interpretation - Springer-Verlag, Berlin, Heidelberg, New-York, Tokyo.

Borillo, A. (1988): "Le lexique de l'espace : les noms et les adjectifs de localisation interne"; Cahiers de Grammaire 13, Toulouse, UTM, pp 1-22.

Borillo, A. (1992): Le lexique de l'espace : prépositions et locutions prépositionnelles de lieu en français - In Hommage à Nicolas Ruwet, L. Tasmowski \& A. Zribi-Hertz (ed.), Communication et Cognition, Ghent.

Borillo, M. (1991): "Sémantique de l'espace et raisonnement spatial" - In Proceedings of the Colloque Sciences de la Cognition, MRT, Paris.

Carlson-Radvansky, L.A. \& Irwin, D.E. (1993): "Frames of reference in vision and language: where is above"; Cognition, 46: 223-244.

Clarke, B.L. (1981): "A calculus of individuals based on "connection"”; Notre Dame Journal of Formal Logic, Vol 22, $\mathrm{n}^{\circ} 3$, pp 204-218.

Clarke, B.L. (1985): "Individuals and points"; Notre Dame Journal of Formal Logic 26, n¹, pp 61-75.

Davis, E. (1989): Representations of commonsense knowledge - Morgan Kaufmann Publishers, San Mateo, California.

Frank, A.U. (1992): "Qualitative spatial reasoning about distances and directions in geographic space"; Journal of Visual Languages and Computing, 1992/3, pp 343-371.

Freksa, C. (1993): "Using Orientation Information for Qualitative Spatial Reasoning" - In Time, Space, Movement, Working Papers of the 4th International Workshop, Château de Bonas, sept. 1992, Aurnague, M./Borillo, A./Borillo, M./Bras, M. (eds), pp 435-452.

Grice, H.P. (1975): "Logic and conversation" - In Syntax and semantics, C.P. Morgan, Academic Press.

Habel, C. (1987): "Cognitive linguistics : the processing of spatial concepts"; T.A. informations, 1987, $\mathrm{n}^{\circ} 2$, pp 21-56.

Hathout, N. (1989): Un modèle logique pour le raisonnement spatial - Rapport de DEA, UPSIRIT, juin 89.

Hayes, P.J. (1985): "The second naive physics manifesto" - In Formal theories of the commonsense world, J.R. Hobbs \& R.C. Moore eds, Ablex Publishing Corporation, Norwood N.J., pp 1-36.

Herskovits, A. (1986): Space and the preposition in English : regularities and irregularities in a complex domain - Cambridge University Press, Cambridge, England.

Jayez, J. (1992): "Document de travail n³" - In Rapport d'activité du groupe inter-prc "Sémantique des Langues Naturelles", juin 92.

Kamp, H. (1979): "Events, instants and temporal reference" - In: Meaning, use and interpretation of language, R. Bäuerle, U. Egli, A. von Stechow (eds.) - de Gruyter, 
Berlin, pp 376-417.

Landau, B. \& Jackendoff, Ray (1993): "What and where in spatial language and spatial cognition"; Behavioural and Brain Sciences, vol 16 n², june 1993, pp 217-238.

Lang, E. (1990): "Primary perceptual space and Inherent proportion schema : two interacting categorization grids underlying the conceptualization of spatial objects"; Journal of Semantics, 7, pp 121-141.

Laur, D. (1991): Sémantique du déplacement et de la localisation en français : une étude des verbes, des prépositions et de leurs relations dans la phrase simple - Thèse de doctorat de l'Université de Toulouse-Le Mirail, Toulouse.

Leech, G. (1969): Towards a semantic description of English - Longman, London.

Miller, G. \& Johnson-Laird, P. (1976): Language and perception - Belknap Press of Harvard University Press, Cambridge, MA.

Pièrart , B. (1979): "Genèse et structuration des marqueurs de relations spatiales entre trois et dix ans"; Cahiers de l'Institut de Linguistique de Louvain (CILL), 5.1-2, pp 41-59.

Pribbenow, S. (1993): "Computing the meaning of localization expressions involving prepositions: the role of concepts ans spatial context" - In The semantics of prepositions: from mental processing to natural language processing, C. Zelinsky-Wibbelt ed., Mouton de Gruyter, Berlin.

Randell D., and A. Cohn (1989): Modelling topological and metrical properties in physical processes - In Proceedings of KR'89, Brachman, Lesveque, Reiter (eds.), Morgan Kaufmann, San Mateo (CA), pp 357-368.

Sablayrolles, P. (1993): "Spatio-temporal semantics in natural language: the case of motion" In Time, Space, Movement, Working Papers of the 4th International Workshop, Château de Bonas, sept. 1992, Aurnague, M./Borillo, A./Borillo, M./Bras, M. (eds), pp 69-88.

Talmy, L. (1983): "How language structures space" - In Spatial orientation : theory, research and application, H.L. Pick \& L.P. Acredolo ed., Plenum Publishing Corporation, NewYork, pp 225-282.

Vandeloise, C. (1986a): L'espace en français : sémantique des prépositions spatiales - Seuil, Paris.

Vandeloise, C. (1986b): "L'avant/l'arrière et le devant/derrière"; Revue Québécoise de Linguistique, vol. 16, n¹, pp 281-308, Université du Québec à Montréal.

Vieu, L. (1991a): Sémantique des relations spatiales et inférences spatio-temporelles : une contribution à l'étude des structures formelles de l'espace en langage naturel - $\mathrm{PhD}$ dissertation, Université Paul Sabatier, Toulouse.

Vieu, L. (1991b): "Spatial semantics : an illustration by the relation dans (in)" - Bhatkar \& Rege (eds), Springer Verlag, Frontiers in knowledge based computing, Springer Verlag, Berlin, 1991 - Proceedings of KBCS'90, Dec. 1990, Pune, Inde. 
${ }^{1}$ I would like to thank Nicholas Asher, Myriam Bras, Laure Vieu and the two anonymous referees for their numerous advice and comments which allow me to improve a lot the content as well as the form of this work. I am also very grateful to Andrée and Mario Borillo for their continuing encouragements and helpful remarks.

${ }^{2}$ In fact, stref is not really a function as we do not presuppose the existence of a space given a priori. It is just a notational trick to isolate purely geometrical aspects of entities from their functional aspects. Formally it can be defined as an equivalence class between entities, which means that several entities may determine the same spacetime portion. For more details see (Aurnague \& Vieu 93).

${ }^{3}$ In this work, we looked at situations in which a deictic orientation is given to an intrinsically oriented entity. However, we adopt a strategy which gives priority to an intrinsic interpretation with respect to a deictic one. So, when the analysed text calls for a spatial relation involving an intrinsically oriented trajector, we first interpret this relation in its intrinsic sense. If the inferences induced by this intrinsic interpretation are not compatible with other elements of the text, then, we try to make a deictic interpretation of the previously mentioned spatial relation.

${ }^{4} \mathrm{~A}$ preliminary study and formalisation of external relations were made some years ago in our group by N. Hathout (Hathout 89) which is akin on various points to the new formal tool we propose.

${ }^{5}$ This notion is necessary in order to grasp the semantic content of prepositions such as devant/derrière (in frontof/behind, § 3.3).

${ }^{6}$ This axiomatics which is grounded on 6 basic relations and their converse, plus identity (in total 13 mutually exclusive relations) has been proposed in (Allen 84) in order to draw calculi on temporal intervals. It makes it possible to grasp the following configurations between two intervals $\mathrm{x}$ and $\mathrm{y}$ :

$\begin{array}{llll}<(\mathrm{x}, \mathrm{y}) & \mathrm{x} \text { precedes } \mathrm{y} & >(\mathrm{x}, \mathrm{y}) & \mathrm{y} \text { follows } \mathrm{x} \\ \mathrm{m}(\mathrm{x}, \mathrm{y}) & \mathrm{x} \text { meets y } & \mathrm{m}_{\mathrm{i}}(\mathrm{x}, \mathrm{y}) & \mathrm{y} \text { meets } \mathrm{x} \\ \mathrm{o}(\mathrm{x}, \mathrm{y}) & \mathrm{x} \text { overlaps } \mathrm{y} & \mathrm{o}_{\mathrm{i}}(\mathrm{x}, \mathrm{y}) & \mathrm{y} \text { overlaps } \mathrm{x} \\ \mathrm{s}(\mathrm{x}, \mathrm{y}) & \mathrm{x} \text { starts } \mathrm{y} & \mathrm{s}_{\mathrm{i}}(\mathrm{x}, \mathrm{y}) & \mathrm{y} \text { starts } \mathrm{x} \\ \mathrm{f}(\mathrm{x}, \mathrm{y}) & \mathrm{x} \text { finishes y } & \mathrm{f}_{\mathrm{i}}(\mathrm{x}, \mathrm{y}) & \mathrm{y} \text { finishes } \mathrm{x} \\ \mathrm{d}(\mathrm{x}, \mathrm{y}) & \mathrm{x} \text { is included (during) in } \mathrm{y} & \mathrm{d}_{\mathrm{i}}(\mathrm{x}, \mathrm{y}) & \mathrm{y} \text { is included in } \mathrm{x} \\ \mathrm{x}=\mathrm{y} & & & \end{array}$

Several axioms are introduced in order to describe composition operations on these relations.

${ }^{7}$ The constraint of spatial connectedness on the studied entities ensures that the extension along a given direction is an interval. Moreover, one may feel it is necessary to fully express these relations in terms of projections of the individuals onto a straight line and of calculations on the resulting intervals (as is usual with Allen's relations). Previously we had in our system a predicate of projection alone with several axioms specifying its behaviour. However, this predicate has not been used here because it would have implied manipulating "abstract" straight lines, points and intervals not having the same status as the ones defined in $\$ 2.1$. We think that such a specification requires a preliminary study of the cognitive processes underlying these operations of projection.

${ }^{8}$ On the basis of this postulate and using the definition of inclusion (relation P of Clarke) as well as several theorems related to Allen's relations, it can be proved for instance that :

$\forall \mathrm{x}, \mathrm{y}, \mathrm{D} \mathrm{P}(\mathrm{x}, \mathrm{y}) \rightarrow \mathrm{sf}=\mathrm{s}_{\mathrm{i}} \mathrm{f}_{\mathrm{i}}(\mathrm{x}, \mathrm{y}, \mathrm{D})$

${ }^{9}$ The function stref gives us the portion of space-time filled by an entity; as a result of the instantaneity constraint previously mentioned, this portion corresponds here to a specific temporal slice temporally bounded by the event (or state) introduced by the NL spatial expression analysed.

${ }^{10} \mathrm{We}$ indicated earlier that, in the framework of this work, we consider only "instantaneous" utterances. However, the properties of intrinsic orientation we define here concern the whole life of the entity (or at least a significant part of it) and therefore they must have a spatio-temporal reading. We are presently working on a temporal translation of such definitions in which directions should also be considered as extended over time (like the other spatio-temporal individuals). e denoting an event and y/e representing a slice of y whose time matches the time of $\mathrm{e}$, a spatio-temporal version of "orient-haut" should be:

Orient-haut(D,x) $\equiv_{\operatorname{def}} \exists \mathrm{y}, \mathrm{z} \operatorname{Dir}-\operatorname{ext}(\mathrm{y}, \mathrm{z}, \mathrm{x})=\mathrm{D} \wedge$ Can-Use $(\mathrm{x}) \wedge \forall \mathrm{e}\left(\left(\operatorname{Event}(\mathrm{e}) \wedge \mathrm{e}_{\mathrm{t}} \operatorname{stref}(\mathrm{x})\right) \rightarrow(\operatorname{In}-\operatorname{Use}(\mathrm{x}, \mathrm{e})>\operatorname{dir}-\right.$ $\operatorname{ext}(\mathrm{y}, \mathrm{z}, \mathrm{x}) / \mathrm{e}=$ haut-grav/e $))$

${ }^{11}$ But not a mere bullet which can only take a contextual orientation.

${ }^{12}$ It can be deduced (from the definition of vertical intrinsic orientation) that when the speaker is in a canonical position, the direction applied to the spatial configuration coincides with the gravitational upper direction.

${ }^{13}$ This specification of "In-sp" is sufficient because we only consider parallelepipedic, spherical or cylindrical entities. If we wanted to take into account more complex shapes (amphitheatres, arches and more generally curved objects) we would have to state a much more complicated formula. We tested the latter for some particular entities and we showed that some interesting inferential properties obtained on the basis of this simple version of "In-sp" were lost. 
${ }^{14}$ Obviously these two sentences may also be interpreted in a deictic way. We assume here that, when a lexeme pointing out a target with an intrinsic frontal orientation is identified in the analysed text, the intrinsic interpretation of the preposition devant is chosen by default.

${ }^{15}$ The relative preference for the alignment of the entities involved in an external or directional preposition greatly depends on contextual factors. For this reason this variable (geometrical) feature has not been integrated in the semantic definition of the preposition devant (in front of) and is controlled at the pragmatic level.

${ }^{16}$ In this case there is no more ambiguity because the two landmarks do not have any intrinsic frontal orientation so that only a deictic interpretation of the preposition devant is possible.

${ }^{17}$ In figure 6 , the deictic orientation of the light given by the speaker Max (facing it) could also be interpreted as a contextual orientation of the light by the armchair. Although it is true that these two orientations coincide in the configuration depicted by figure 6 , we should recall that, in the framework of this study, we only take into account intrinsic and deictic orientational processes.

${ }^{18}$ The numbering of these definitions does not necessarily imply a greater acceptance for the spatial relation under consideration. For instance, although two entities verifying the axial priority 2, 3 or 4 will be more "in front of" than if they were in the configuration 1, it is not always clear which of the configurations 2,3 or 4 is the best. 